\title{
Energy Management and Energy Crisis in Textile Finishing
}

\author{
Faheem Uddin ${ }^{*}$ \\ Textile Engineering Department, FoE, Baluchistan University of I. T. Engineering and Management Sciences, Airport Road, Balali, \\ Quetta \\ *Corresponding author: Faheem.Uddin@buitms.edu.pk
}

Received May 05, 2014; Revised May 15, 2014; Accepted May 28, 2014

\begin{abstract}
Textile industry is indeed one of the major energy consumers. Therefore, approaches introducing reduced energy processing of textiles in association with the standard energy management practices would be in obvious demand. Energy management standard is particularly desired for energy- intensive industrial sectors. Textile finishing organizations significantly depends upon the continual energy supply from fiber production to finished fabric. Textile processing areas that heavily consume water and electricity can be significantly improved in terms of reduced energy utilization and minimum energy loses through exercising improved housekeeping and standard management practices. It was perceived that ISO 50001 standard will provide management guideline and approaches to the textile sector organizations leading to an increased efficiency, reduced cost through less energy consumption, and improved energy performance. Any scientific information and data on hot air, heat, steam and processed water recycling available in literature would indeed be beneficial to enhance textile processing and finishing industry in the utilization of energy management policy, performance and efficiency measures, physical structure. The important factors that would be influenced by the energy management standard in textile finishing, ranging over fiber processing, pre- treatments, dyeing, printing, and special effects, are identified for improvement and discussed in this paper.
\end{abstract}

Keywords: energy management, ISO 50001 standard, textile finishing

Cite This Article: Faheem Uddin, “Energy Management and Energy Crisis in Textile Finishing.” American Journal of Energy Research vol. 2, no. 3 (2014): 53-59. doi: 10.12691/ajer-2-3-2.

\section{Introduction}

When several countries in South Asia were experiencing serious challenges in meeting the continual energy supply for industrial and domestic sector, and to assist the reduction in unit product cost through reducing the dollar price of unit energy consumption; the ISO (International Organization for Standardization) was launching ISO 50001 on energy management systems at the Geneva International Conference Center on July 17, 2011.

At times when energy reserves depletion was considered serious in industrialized regions; and energy crisis for industrial and domestic sectors had witnessed the massive demonstrations on roads and streets in several areas of SAARC region, and the industrial sectors were opting to consider the reduction in production schedules; the introduction of ISO 50001 energy management systems is optimistically desired to reduce the degree of energy scarcity crisis (Figure 1).

The worldwide realization of energy conservation coupled with the greener and efficient utilization of energy is evident from forty five participating countries, and fourteen observing countries associated with the development of ISO energy management standard.
Consequently, the ISO technical committee on energy management (TC 242), created in 2008, was successful to produce ISO 50001: 2011 in June 2011 [1].

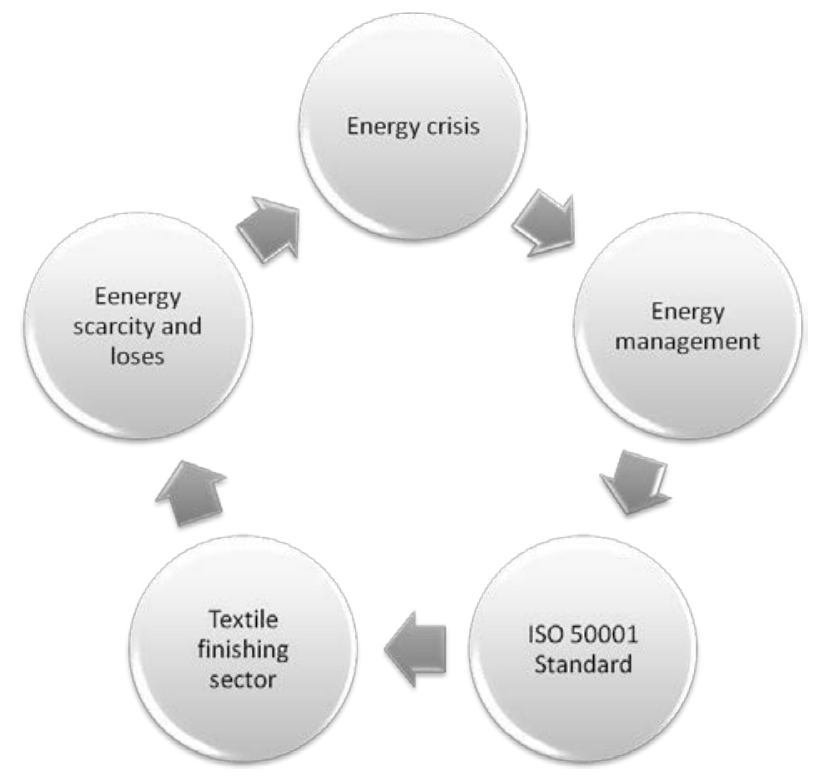

Figure 1. Textile finishing sector and ISO 50001 standard

The principal desire was to provide a systematic approach to an organization for continual improvement of 
energy performance; its use and consumption. That improvement may be achieved using the requirements specified in ISO 50001: 2011, through measurement, documentation, reporting, design and procurement practices for equipment, system, process and personnel [2].

The purpose of this study is to find out the implications of ISO 50001: 2001 quality management system on the textile finishing sector and to identify the research areas for efficient energy utilization based on the quality management practices. Optimistically, the identified research subjects will provide an effective solution for energy crisis. Textile finishing in terms of improved energy performance and reduced energy consumption is explored to assist the possible elimination of energy crisis through energy management.

\section{Perceivable Advantages from Energy Management}

The ISO standard 50001 may be imagined to influence the management of $60 \%$ of world energy consumption. That includes $7 \%$ by the commercial sector (business institutions, service providing organizations) and $51 \%$ by the industrial sector (manufacturing, agriculture, construction and mining) [3].

Significant optimism was shown in the introduction of ISO 50001 standard for improving the energy management practices, and bringing definite benefits in energy performance in an organization practicing the ISO 50001 standard. Rob Steele, ISO Secretary General has commented “...... Improved energy performance can provide rapid benefits for an organization by maximizing the use of its energy sources and energy- related assets, thus reducing both energy cost and consumption. The organization will also make positive contributions toward reducing depletion of energy resources and mitigating worldwide effects of energy use, such as global warming”. Particular concern for the multinational organizations was indicated as “...... Multinational organizations will have access to a single, harmonized standard for implementation across the organization with a logical and consistent methodology for identifying and implementing improvements" [4].

The important advantages perceived for an organization through an effective implementation of ISO 50001 Standard may be summarized as [3,4]:

1. Assisting an improvement in the use of the existing energy- consuming assets

2. Introducing the transparency and facilitate communication for the management of energy resources

3. Promoting the motivation for energy managementbest practices

4. Evaluating and prioritizing the implementation of energy- efficient technologies

5. Developing a framework over the supply chain for energy efficient practices

6. Supporting the improvement for greenhouse gas emission reduction projects

7. Other management systems including environmental, health and safety can be integrated with this (ISO 50001) energy management standard.

\section{Realization of Energy Crisis in Processing Industry}

The climatic change concerns for a greener society, and the depletion of conventional energy reserves had indicated the significance of sustainable and renewable energy means. With the reduction in fossil energy reserves and global warming effects; the alternate energy sources were receiving the attention. For example hydrogen generation, was reviewed if use of hydrogen in a polymer electrolyte membrane (PEM) fuel cell was to become the prime power generation source for stationary and mobile applications [5].

Table 1. Important textile processes consuming significant amount of energy

\begin{tabular}{|c|c|c|c|}
\hline S.no & Process name & Energy requirements & Remarks \\
\hline 1. & $\begin{array}{l}\text { Fiber } \\
\text { production }\end{array}$ & $\begin{array}{l}\text { Electricity in machine } \\
\text { operation, water and } \\
\text { chemicals used, heating in } \\
\text { drying }\end{array}$ & $\begin{array}{l}\text { In a typical fiber production the energy consumed can be } 21 \% \text { if total energy used from fiber } \\
\text { to finished fabric produced [9]. }\end{array}$ \\
\hline 2. & Spinning & Mainly electricity, fuel. & $\begin{array}{c}\text { In a typical spinning process the energy consumed can be } 18 \% \text { if total energy used from fiber } \\
\text { to finished fabric produced [9]. }\end{array}$ \\
\hline 3. & Weaving & Mainly electricity, fuel & $\begin{array}{l}\text { In a typical fiber production the energy consumed can be } 11.4 \% \text { if total energy used from } \\
\text { fiber to finished fabric produced [9]. }\end{array}$ \\
\hline 4. & Sizing & Electricity, water, fuel & $\begin{array}{l}\text { Heating and drying would be required. In typical example of cotton, 500- } 8200 \text { liters of water } \\
\text { per1000 kg of cotton may be required in the process [11]. }\end{array}$ \\
\hline 5. & Singeing & Electricity, fuel & \\
\hline 6. & Desizing & Electricity, water, fuel & $\begin{array}{l}\text { Heating in the process andfor drying of processed fabric is required.In typical example of } \\
\text { cotton, 2500- } 21000 \text { liters of water per } 1000 \mathrm{~kg} \text { of cotton may be used [11]. }\end{array}$ \\
\hline 7. & Scouring & $\begin{array}{l}\text { Electricity, water and } \\
\text { chemicals, fuel }\end{array}$ & $\begin{array}{l}\text { Heating and steaming during the process and drying for the processed fabric is required. In } \\
\text { typical case of cotton, 20,000- 45, } 000 \text { liters of water per } 1000 \mathrm{~kg} \text { of cotton may be used } \\
\text { [11]. }\end{array}$ \\
\hline 8. & Bleaching & $\begin{array}{l}\text { Electricity, water and } \\
\text { chemicals, fuel }\end{array}$ & $\begin{array}{l}\text { Heating and steaming during the process and drying for the processed fabric is required. In } \\
\text { typical case of cotton, 25, 00- } 25,000 \text { liters of water per } 1000 \mathrm{~kg} \text { of cotton may be used [11]. }\end{array}$ \\
\hline 9. & $\begin{array}{l}\text { Mechanical } \\
\text { finishing }\end{array}$ & Electricity, water, fuel & Heating, steaming, compressing, setting, and drying can be required. \\
\hline 10. & $\begin{array}{l}\text { Dyeing and } \\
\text { finishing }\end{array}$ & $\begin{array}{l}\text { Electricity, water, chemicals, } \\
\text { fuel }\end{array}$ & $\begin{array}{l}\text { Heating during the process in dye liquor, steaming, soaping, washing and drying is required. } \\
\text { In a typical dyeing and finishing operation the energy consumed can be } 25 \% \text { of total energy } \\
\text { used from fiber to finished fabric produced [9]. For cotton, the water consumed may be } 10 \text {, } \\
000-300,000 \text { liters per } 1000 \mathrm{~kg} \text { [11]. }\end{array}$ \\
\hline 11. & Printing & $\begin{array}{c}\text { Electricity, water, chemicals, } \\
\text { fuel }\end{array}$ & $\begin{array}{l}\text { Heating during the process, and during steaming, soaping, washing and drying is required. } \\
\text { For cotton, the water consumed may be } 8,000-16,000 \text { liters per } 1000 \mathrm{~kg}[11] \text {. }\end{array}$ \\
\hline
\end{tabular}


An overview of using the supercritical carbon dioxide in textile processing was presented to describe how the reduced environmental effects and increased energy saving were achievable [6]. Significant reduction in water consumption is potentially achievable through the use of supercritical fluid $\left(\mathrm{CO}_{2}\right)$ in the processes of yarn preparation, dyeing, and finishing. Supercritical carbon dioxide textile processing, relative to conventional aqueous processes, offers several beneficial effects including significant reduction in water consumption, elimination of hazardous industrial effluent, reduced energy consumption (since absence of water would eliminate the consumption of heat energy used in drying and fixation stages subsequent to dyeing), and an enhanced level of production. Moreover, reduction in water, chemicals and auxiliaries results in reduced emission of gases/ vapors/ air emissions. Important textile processes that consumes significant amount of energy are presented in Table 1.

Another important approach that was pursued to offer reduced water utilization in textile processing was the plasma treatment of fibrous materials. For example the cotton and wool fabrics, following the low- temperature treatment, showed 50\% improved hydrophilicity in the subsequent scouring and dyeing processing. The contact angle, and wicking properties of cotton and wool fabrics were improved by the low- temperature plasma treatment [7].

Processing textile substrates from fiber to fabric through finishing, coloration and garment manufacturingall the phases are energy intensive. Any inconvenience in energy supply resulting from the dollar price or 'load shedding' had serious and direct influences in cutting down the industrial production.

In several Asian countries including China, India, Pakistan, Bangladesh, Sri Lanka, Indonesia, Thailand etc., textile and clothing production is an important industrial sector making significant contribution in national economy. In these regions textile and clothing production depends upon the continual supply of energy at reduced unit price.

Industrial Associations in Pakistan have recently shown serious concerns for energy requirements in several Industrial Estates located across the country in Lahore, Karachi and Faisalabad. Several industrial units in textile sector were ended with the option of reducing production.

In some of the South Asian countries the energy production and supply are under the significant control of public sector organizations, however, the users are mainly the private organizations. Possibly, the ISO 50001 standard will mainly be desired by the energy users to beneficially improve the production, and to maximize the process output using a given amount of energy.

An example case may be seen in Jiangsu Province of China that experienced fast economic development. It was indicated that with the economic development and industrialization the demands for energy was significantly increased. The supply of local primary energy was 23\% of the demand. The desired energy consumption rose to 78 Mtce (1 tce $=7,000,000 \mathrm{kcal}), 78 \%$ of which was for industry and construction sector [8].

Organizational and product competitiveness, process and product cost reduction; technological- industrial advancement and prompt schedule delivery are significantly affected by the provision and management of energy.

\section{Energy Performance Factors in Textile Processing}

The industrial units would avail the opportunity to enhance the energy performance. It should be principally leading to an improved use of energy sources, and energyrelated physical structure. If the ISO 50001 standard is realistically implemented by energy consuming sector, particularly the energy- intensive manufacturing industries like textile and clothing producers, it may be resulted in significant reduced depletion of energy resources, and mitigation in the worldwide effects of energy consumptions including global warming; and probably more mature bilateral political relations towards the search and consumption of energy reserves around the world.

Studies demonstrated the important areas from fiber production to textile fabric processing where energyefficient processing stages were possible [9,10,11]. Water and energy conservation in textile processing is highly demanding. Factors causing the energy scarcity and loses in textile finishing sector are shown in Figure 2. It is known that textile industry can be appreciated for an energy saving up to 10 percent through basic housekeeping enhancement including energy management and auditing. Textile dyeing and finishing is prominent sector in consuming energy. From fiber production to clothing manufacture 25 percent of total energy consumed was utilized in dyeing and finishing [12]. Therefore, improved and alternative methods would be desired to reduce the energy loses and consumption in dyeing and finishing.

In terms of fiber mass, the energy consumption can be differentiated for dry and wet processing. The energy consumed in dry processes, knitting and weaving stands at $1.2 \mathrm{kWh} / \mathrm{kg}$, and $6.2 \mathrm{kWh} / \mathrm{kg}$ respectively; however, for finishing it rose to $17.9 \mathrm{kWh} / \mathrm{kg}$ [13]. Steaming, drying, curing and other heating operations in finishing consume significant energy.

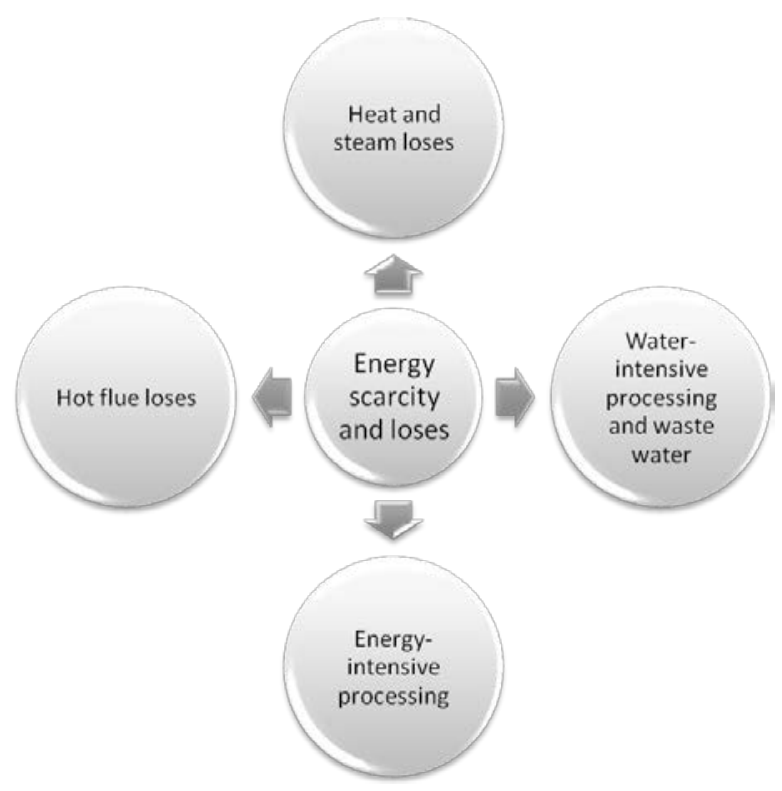

Figure 2. Factors in textile finishing causing energy scarcity loses

Amount of water consumption in typical textile industry may be indicated by a textile mill producing denim fabric. The processes performed were included 
cotton fiber spinning, fiber dyeing, sizing and finishing. The mill was operated 24 hours/ day, with 3 shifts/ day. It was producing 20, 000 tons of denim fabric per year, with water consumption rate of $2000 \mathrm{~m}^{3} /$ day, and the chemical consumption was approximately 1000 ton/ month [14].

Modifying the finish bath formulation used for producing the fading effects in dyed cotton jeans was shown to reduce the cost of the process and water consumption [15].

The total amount of chemicals consumed in textile mills may range over $10 \%$ to $100 \%$ on weight of the fabric. The textile industry is also known as one of the major waste water producers to environment. It was indicated that on an average $160 \mathrm{Kg}$ of water were required to produce 1 $\mathrm{Kg}$ of textile product. All the water applied, and a significant content of chemical finishes, following the application requires heat energy in drying and fixation. Moreover, there are several wet and dry states of fabric where the desired high temperature achieved through electrical energy.

The realization of energy- intensive nature of textile processing had seen several research interest and measures aimed at reducing the overall energy consumption including combined finishing processes, combined finishing and coloration processes $[16,17,18]$, low liquor processing techniques, low temperature drying, singlestep drying and curing, foam finishing; use of alternative energy sources (for example use of UV drying against the conventional drying using hot flue) [19]; and alternative methods consuming reduced energy (for example plasma finishing, supercritical $\mathrm{CO}_{2}$ dyeing/ finishing), and energy and water conservation through recycling of dyeing waste water [20] etc (Table 2). Therefore, several advantageous effects in textile finishing are achievable through the energy management practices in process performance, and operating appropriate machines (Figure 3).

Table 2. Approaches used in textile processing for reducing energy consumption

\begin{tabular}{|c|c|c|}
\hline S.no & $\begin{array}{c}\text { Approaches used for reduced energy } \\
\text { consumption }\end{array}$ & Example/ Remarks \\
\hline 1. & Combined special finishing processes & For example combining easy- care and flame retardant finishing [12]. \\
\hline 2. & Combined processing stages in finishing & To perform drying and curing operation simultaneously. \\
\hline 3. & Combined finishing and coloration processes & For example to perform dyeing or printing in combination with easy- care finishing [16,17,18]. \\
\hline 4. & Low liquor processing techniques & $\begin{array}{c}\text { Dyeing or finishing processes where fixation can be done at reduced liquor ratio resulting in } \\
\text { reduced energy requirement in drying. }\end{array}$ \\
\hline 5. & Low temperature drying & $\begin{array}{c}\text { Development of finish liquor composition that permits the finish effect or finish fixation at } \\
\text { reduced temperature. }\end{array}$ \\
\hline 6. & Utilization of alternative energy sources & For example use of UV drying against the conventional drying using hot flue [19]. \\
\hline 7. & $\begin{array}{c}\text { Alternative processing techniques consuming } \\
\text { reduced energy }\end{array}$ & For example plasma finishing, supercritical $\mathrm{CO}_{2}$ dyeing/ finishing), \\
\hline 8. & Energy and water conservation. & For example recycling of waste water from scouring, bleaching and dyeing processes etc. [20]. \\
\hline
\end{tabular}
released from dryer was re- circulated directly into burner combustion zone, and blended with fresh air. The blended air was subsequently forwarded to the dryer [21].

Possibly, with reference to textile processing when the machines used in industry for dyeing and curing operations; three important stages where efficient energy management practices would be significantly beneficial include the following:

1. Minimizing the energy loses produced in fiber processing machines, during down time setting; and those resulting from the use of impaired components in machines etc.

2. Underutilization of process machinery efficiency for example excessive heat consumption in reaching a desired degree of drying temperature.

3. An assessment of overall energy management practices within a particular processing industry, and developing an improved matching of energy resources and energy uses.

The realization of energy intensive character of textile finishing had been the subject of research and development in the textile finishing machine manufacturers; where the latest advancement were in the market in coming ITMA, September 2011 [22].

Generally, all the important machine manufacturers

\section{Processing Machines and Energy Performance} have attempted to design and produce machines with reduced level of water or energy consumption as a significant machine characteristic exhibited in the processes desired by the textile finishing industry.

For example, Benninger AG introduced resource management in machine development that aimed at energy efficient solution to finishing industry [22]. The multi- stage diaphragm system has the first stage of 
ultrafiltration of used water coming from finishing process; subsequently, the water was treated in reverse osmosis. The ultrafiltration was performed using a special ceramic diaphragm frame designed to remove long chain organic components, and the following reverse osmosis separated the dissolved dyestuff and salts from the processed water. The diaphragm used water recovery system that was claimed to recover more that $80 \%$ of water.

Alternately, the different membrane processes have been investigated at pilot scale for designing a plant set up to assess the possibility of recycling the textile processing wastewater. Sand filtration and ultrafiltration were used in the pilot plant as pretreatment prior the membrane process using nanofiltration or reverse osmosis. The ultrafiltration module tested was relatively working at low pressure, therefore, consuming low energy costs. It provided a constant permeate to next membrane process (nanofiltration or reverse osmosis). The hardness removal achieved was 75\%, and more than 90\% using nanofiltration, and reverse osmosis respectively [23].

Another type of energy- efficient technology development, introduced for heat recovery in textile finishing may be seen in Eco- heat system developed by Bruckener.

The Eco- heat system utilized the heat energy of exhausted air and directed it to heat fresh air entering to stentor. The system may also direct the exhausted air to heat the water for a finishing process. A similar concept of re- using the wet processing water and heat energy was presented in poster exhibition, indicating the realization of energy- efficient textile finishing process [24].

Most fibrous forms are processed in water in any textile mill. The wetting of fibers subsequently, requires drying operation to remove excess liquid content. Generally, stentor machines are used to perform the continuous drying operation. The stentor system may include circulating and induced air draft fans, a hot oil boiler and oil circulating pump. The exergy efficiencies of stentor and hot oil boiler were found to be $28.7 \%$ and $34.7 \%$ respectively; and the overall value for system was 34 . $4 \%$ [25].

\section{Process Specific Factors in Energy Management}

Energy conservation through energy management; and energy efficiency using best practices can be appreciated in reducing the energy cost of any specific textile processing. Drafting the best available techniques is, therefore, important. The use of resources and textile processing emissions were studied for the chain of wet processing in selected Finnish textile companies [26]. It was revealed that:

1. No significant differences in energy and water consumption between continuous and batch wet processing could be measured. However, jet machines were using the lowest dyeing liquor ratios, and winch dyeing machines were working with the highest liquor ratios.

2. Dyestuff consumption depends upon the color shade required; dyes with low fixation level, such as reactive and sulphur dyes were at $60 \%$ fixation level on average, were releasing more polluted effluent.
3. Approximately, $20 \%$ of the process liquor having unfixed dyestuffs and auxiliaries was discharged in sewage treatment plant.

The consumption of significant amount of water in fiber processing may be traced in cotton fiber production. It has received obvious criticism for improving the water and pesticide management practices.

Cotton fiber production is the major water consuming sector in the country where it is produced. It was indicated that general lack of an appropriate water pricing mechanism or lack of other means of generating production information, cotton consumers were having negligible incentives to practice the responsibility for the alarming impacts on water resources depletion [27].

Water and heat are the two most visible form of energy consumed throughout the fiber and textile production and subsequent processing. Possibly following the cotton crop production, that is the major water consuming process, a single cotton shirt approximately requires 2, 800- 3000 liters of water where wet finishing operations consumes most of water. However, the water and energy intensive character of textile finishing is not limited to cotton only. Generally, finishing of any fiber consumes significant water and heat energy.

The energy cost proportion in percentage of the total turnover textile finishing industry was typically shown 25\% in 2008 for typical textile finishing in Germany [28]. The energy intensive textile finishing processes shown were included drying, curing, heat setting, fixing, condensation, cross- linking, moist cross- linking, thermosol dyeing etc.

The conventional textile processing sector would require improving the data and scientific information for each type of processes to enhance the benefiting effects of energy performance- management guidelines provided in ISO 50001 Standard.

\section{Characteristics of Energy Consuming Organizations}

An assessment of interest and responsiveness to energy management through the energy conservation and energy performance improving practices may reveal the variation from organization to organization in reacting to the requirements of the energy management standard.

The characteristics of each firm in consuming energy would be different when translated to energy- saving practices. An appreciation of energy management and standard guidelines coupled with the model case studies would be important in supporting the introduction of ISO 50001 Standard to textile industries in developing regions where management system has reduced recognition.

Therefore, the investment behavior, interest in energy policy, and responsiveness to energy performance would require empirical investigation [29]. The variation in energy consuming practices is obvious realizing the diversity in the utilization of machinery, process types and involved processing stages, type and amount of chemicals and water used, types of released hot vapors and gases, temperature and amount of effluent.

Probably, the traditional textile processing industry in Turkey, being one of the major home textile products exporters, has appreciated the specific energy 
consumption and cost for a particular production to estimate the future consumption in textile sector [30].

The waste minimization procedures introduced by the US Environmental Protection Agency (USEPA), and some additional steps were used in a textile dyeing mill. The analysis of steam distribution, steam utilization, and the condensate systems had shown interesting findings. It revealed the reduction in waste water by $21 \%$; textile auxiliaries and chemicals by $14 \%$, and steam usage by $25 \%$. The payback period of proposed approach was less than one year [31].

Useful information on energy consumption and energy performance may be generated through in- depth interview, surveys, and industrial process studies for evaluating the energy- saving investments and required organizational measures [32].

\section{Conclusions}

The declining state of conventional energy reserves and energy crisis in several countries has indicated the demands of energy management standard. It is particularly desired for energy- intensive industrial sectors. Textile finishing and processing organizations significantly depends upon the continual energy supply in meeting the production schedules, however, without the development of an improved energy management system in the organizations, it may experience an increasingly undesired energy crisis.

Therefore, the strategies would indeed be desired in manufacturing and material processing sectors like the garment denim manufacturing; and textile processing. It is optimistically perceived that ISO 50001 standard will provide management guideline and approaches to the public and private sector organizations leading to an increased efficiency, reduced cost through less energy consumption, and improve energy performance.

Any techno- scientific information and data on hot air, heat, steam and processed water recycling available in literature would be beneficial to textile processing and finishing industry in the utilization of energy management policy, performance and efficiency measures for assessing economic viability and the investment of capital, physical structure and human resource in energy management practices coupled with the synergistic compatibility with the already existing interest and resources of organizational system.

In energy intensive organizations where quality assurance management has received significant recognition, perhaps it would there be more attractive to assess the required adoption of energy management system, however, the traditional energy- intensive textile processing mills particularly those in developing countries might experience the reduced recognition of the system management in general. However, the ISO 50001 standard provide a standard frame work for integrated management practices generally useful in reducing the energy crisis.

\section{References}

[1] ISO, TC 242, Energy Management, p 1. 2011. Home page, www.iso.org
[2] ISO, ISO 50001, Energy management systems requirements with guidance for use, p 1. 2011. Home page, www.iso.org

[3] ISO, ISO Document Ref: 1434, ISO Launches ISO 50001 energy management standard, p 1. 2011. Home page, www.iso.org

[4] Edwin Pinero, Energy excellence in the ISO 50001 energy management system standard, ISO Focus, pp. 8-10. 2011.

[5] Mandal T. K, D. H. Gregory, 2010, Hydrogen: A future energy vector for sustainable development, Proc. IMech E, Volume 224 Part C: J Mechanical Energy Science, 539. 2010.

[6] Gerardo A. Montero, Carl B. Smith, Walter A Hendrix, Donald L. Butcher, Supercritical fluid technology in textile processing: An overview, Ind. Eng. Chem. Res., 39 (12). 4806. 2000.

[7] D. Sun, G. K. Stylios, 2004, Effect of low temperature plasma treatment on the scouring and dyeing of natural fabric, Textile Research Journal, 74 (9). 751.2004.

[8] Xiaohua Wang, Zhenmin Feng, Energy consumption with sustainable development in developing country: a case in Jiangsu, China, Energy Policy, 31 (15). 1679. 2003.

[9] UNIDO, Textile industry: Output of a seminar on energy conservation in textile industry, UNIDO and Ministry of International Trade and Industry (Japan), pp. 1-9. 1992.

[10] Hasanbeigi A., Energy-efficiency important opportunities for the textile industry, China Energy Group, China Sustainable Energy Program, US Department of Energy, pp. 1-136. September 2010.

[11] Ayaz M. S., Water conservation in textile industry, Pakistan Textile Journal, November Issue, 48-51. 2009.

[12] Faheem Uddin,Recent development in combining flame-retardant and easy-care finishing for cotton, Cellulose Chem. Technol., 47 (5-6). 469-477. 2013.

[13] Rup J, Steaming, drying, curing and other heating operations in finishing consume significant energy, pp. 1-2. 2010. Home Page, http://www.textileworld.com

[14] Ozturk E., Yetis U., Dilek F.B., Demirer G.N., A chemical substitution study for a wet processing textile mill in Turkey, Journal of Cleaner Production, 17 (2). 239-247. 2009.

[15] Faheem Uddin, Zaheer Khan, Investigating the fading effects of indigo dyed denim jeans in local industry, BS Capstone Project, pp. 42-44. 2009. University of Management and Technology, Lahore.

[16] Faheem Uddin, Lomas M., Combined crease recovery finishing and pigment printing, Coloration Technology, 121 (3), 158-163. 2005.

[17] Yongchun Dong, Jijun Wang, Pengfei Liu, Dyeing and finishing of cotton fabric in a single bath with reactive dyes and citric acid, Coloration Technology, 117 (5). 262. 2001.

[18] Hyung-Min Choi, One-bath dyeing and nonformaldehyde durable press finishing of cotton using dialdehyde and a monochlorotriazinyl reactive dye, Textile Research Journal, 72 (6). 469. 2002.

[19] Faheem Uddin, Lomas, M., Pre-and post-finishing of pigment and reactive prints. Textile Asia, October Issue. 45-52. 1996.

[20] Ali M. El-Nashar, Energy and water conservation through recycle of dyeing wastewater using dynamic $\mathrm{Zr}$ (VI)-PAA membranes, Desalination, 33 (1). 21. 1980.

[21] Benjamin H. Freze, Fuel saving apparatus and method for textile drying and finishing, USP 3, 995, 988. 1976.

[22] Fibre2fashion.com, Energy saving techniques: Spotlight of finishing sector, p 1. 2011. Home page www.fibre2fashion.com.

[23] M. Marcucci, G. Nosenzo, G. Capannelli, I. Ciabatti, D. Corrieri, G. Ciardelli, Treatment and reuse of textile effluents based on new ultrafiltration and other membrane technologies, Desalination, 138 (1-3), 75. 2001.

[24] Faheem Uddin, Water and heat recycling in textile wet processing, Poster exhibition, Department of Applied Chemistry (Polymer and Textile Technology Section). 1992. University of Karachi, Karachi.

[25] Cay A., I. Tarakcioglu, A. Hepbasli, Exergetic performance assessment of a stentor system in a textile finishing mill, International Journal of Energy Research, 31 (13). 1251. 2007.

[26] Eija Kalliala, Paivi Talvenmaa, Environmental profile of textile wet processing in Finland, Journal of Cleaner Production, 8 (2). 143. 2000.

[27] Chapagain A. K., A. Y. Hoekstra, H. H. G. Savenije, R. Gautam, The water footprint of cotton consumption: An assessment of the impact of worldwide consumption of cotton products on the water resources in the cotton producing countries, Ecological Economics, 60 (1). 186. 2006. 
[28] PLEVA Sensors and Controls, News 2009, pp. 1-2. 2009.

[29] Henri L. F. de Groot, Erik T. Verhoef, Peter Nijkamp, Energy saving by firms: Decision making barriers and policies, Energy Economics, 23 (6). 717. 2001.

[30] Harun Kemal Ozturk, Energy usage and cost in textile industry: A case study for Turkey, Energy, 30 (13). 2424. 2005.
[31] Petek J., P. Glavi, An intergral approach to waste minimization in process industries, Resources Conservation and Recycling, 17 (3), 169. 1996.

[32] GruberEdelgard, Michael Brand, Promoting energy conservation in small and medium-sized companies, Energy Policy, 19 (3). 279. 1991. 